\title{
Planejamento interpretativo do patrimônio cultural histórico e arquitetônico da região central da cidade de Castro - PR
}

\section{Downtown Castro (Paraná state) interpretative planning: architectural, historic and cultural heritage}

\author{
Paulo Roberto Bannach Pucci (PUCCI, P. R. B.) ${ }^{*} \mathrm{e}$ \\ Poliana Fabíula Cardozo (CARDOZO, P. F.) ${ }^{* *}$
}

\begin{abstract}
RESUMO - O patrimônio cultural histórico e arquitetônico representa um importante atrativo para o turismo, quando proporciona novas propostas para o desenvolvimento das cidades. O desafio dos planejadores do turismo é conciliar o uso turístico do patrimônio com a sua preservação. Na procura por esta convivência o planejamento interpretativo sinaliza como saída para o uso sustentável do mesmo, pois ele estabelece uma relação entre este atrativo com o visitante oferecendo informações que o levam a revelar sua identidade. Neste trabalho, o patrimônio cultural histórico e arquitetônico do centro da cidade de Castro (PR) é levantado e analisado por meio dos preceitos do planejamento interpretativo. Concluindo que este tem um potencial turístico, e assim facilitando novas ações para o uso do patrimônio pelo turismo
\end{abstract}

Palavras-chave: Turismo; Patrimônio cultural; Planejamento interpretativo; Castro-PR.

ABSTRACT - The architectural, historical and cultural heritage represents an important attractive for the tourist, when it providing new proposals for the development of cities. The challenge of the planners of the tourism is to conciliate the tourist use of this heritage with its preservation. For this relation with the interpretative planning signals as answer for the sustainable use of the heritage, therefore it establishes a relation of the heritage with the visitor offering information that permits to disclose the identity and the of the heritage. In this essay, the architectural, historical and cultural heritage of $\mathrm{Castro} / \mathrm{PR}$ is inventoried and analyzed through the rules of the interpretative planning. Concluding that this has a tourist potential, and this facilitating new actions for the use of the heritage for the tourism.

Key words: tourism; cultural heritage; interpretative planning; Castro City - Paraná State.

\footnotetext{
* Bacharel em Turismo pela Universidade Estadual do Centro-Oeste, Irati - PR. Endereço: Universidade Estadual do Centro-Oeste / Departamento de Turismo: PR 153 Km 7 - Riozinho. CEP: 84500-000 - Irati -PR. Telefones: (42) 3421-3000.E-mail:paul_pucci@ hotmail.com.

** Bacharel e Mestre em Turismo (Unioeste/UCS). Doutoranda em Geografia (UFPR). Docente do Curso de Turismo da Universidade Estadual do Centro-Oeste, pesquisadora na modalidade continuada da mesma IES. Endereço: Universidade Estadual do Centro-Oeste / Departamento de Turismo. PR $153 \mathrm{Km} 7$ - Riozinho. CEP: 84500-000 - Irati - PR. Telefones: (42) 3421-3000. E-mail: polianacardozo@yahoo.com.br. (42 9974 1716).
} 


\section{INTRODUÇÃO}

A cidade de Castro está localizada na região central dos Campos Gerais, micro região do estado do Paraná, a 159 km da capital, Curitiba. Tem sua economia baseada na agropecuária. Castro teve fundamental importância na colonização dos Campos Gerais, região desenvolvida durante a atividade econômica do tropeirismo. Esta colonização é retratada por meio do centro histórico, pela sua arquitetura do século XVIII e XIX, arquivo documental e peças expostas no museu e nas casas de exposições artísticas. A cidade é o centro da região turística paranaense denominada Campos Gerais, que tem na Rota dos Tropeiros seu maior projeto turístico de roteirização, e pode ser citada como um exemplo de localidade preocupada com a história e a cultura local. Sendo assim, trabalha na recuperação de espaços históricos esquecidos durante muito tempo pela sociedade local. Desta forma, a sociedade busca dar novos usos para estes espaços ainda existentes.

A pesquisa que aqui se apresenta visou identificar os principais espaços com potencialidade para o turismo histórico existente no centro de Castro e o cruzamento desses dados com os preceitos do planejamento interpretativo, para vislumbrar possibilidades para a atividade turística.

Observando a cidade de Castro podem-se distinguir as construções mais antigas das mais recentes, tomando como base o estilo das casas com relação ao contexto do período em que se passava o país na época de suas construções, que nesta questão, a região de Castro era a fase do tropeirismo e o início de uns dos ciclos de imigração no Brasil. O centro de Castro, que além de abrigar toda a administração da cidade, é o principal local de comércio, contendo fluxo de turistas mediano (sem nenhum planejamento ou pesquisa que ateste esse fluxo, além da observação) em função da atratividade do Museu do Tropeiro $^{1}$ e Museu da Sinhara ${ }^{2}$, que mantêm a cultura do tropeirismo.

Desta feita, esta pesquisa teve por objetivos: refletir sobre uma possível implementação de planejamento interpretativo do patrimônio arquitetônico tombado e não tombado da cidade de Castro /PR.

\footnotetext{
${ }^{1}$ Museu destinado à cultura do Tropeirismo.

${ }^{2}$ Museu destinado à mulher do tropeiro.
} 


\section{METODOLOGIA DE PESQUISA}

Para análise da pesquisa e para alcançar com sucesso todos os objetivos, a metodologia utilizada valeu-se de várias etapas que em conjunto levam à cientificidade da questão. Na primeira etapa, houve necessidade de se fazer um referencial teórico, nos temas relacionados à cultura, patrimônio cultural e planejamento e suas interfaces com o turismo. Outra etapa deu-se por meio de coleta de dados, que foi realizada no mês de Julho de 2007, em casas que possuíam 90 anos ou mais de construção, por meio de entrevistas pessoais, fazendo uso de um plano de entrevista, e um formulário adaptado do modelo de formulário de inventário do Ministério de Turismo, foram selecionados para as entrevistas os proprietários atuais das casas. No total, foram levantadas 23 construções no centro de Castro e todos responderam à entrevista.

Após as entrevistas e o preenchimento dos formulários, os dados obtidos foram analisados para permitir a identificação do patrimônio e a sua valorização, a fim de ter informações necessárias para a próxima e última etapa que consistiu no direcionamento do planejamento interpretativo do centro histórico de Castro. Nesta etapa foram cruzados os dados para dar possíveis sugestões de utilização do patrimônio pelo turismo.

\section{TURISMO, LEGADO CULTURAL E SUAS INTERFACES}

O turismo visa, entre outros objetivos, a busca de novos segmentos e o turismo cultural pode ser apresentado como uma das grandes tendências do setor, pois existe uma intensa procura pela história e etnicidade. Nesta perspectiva o patrimônio cultural no Brasil é diversificado, pelas várias formas de colonização e exploração do seu território.

O turismo por deter um mercado variado, proporciona a formatação de uma infinidade de produtos que atendem a muitos tipos de turistas. Atualmente o turismo como forma de lazer é praticado pelo sujeito para fuga do seu cotidiano, em busca de novas experiências culturais e sociais que lhe tragam prazer e bem-estar. Entre essa 
infinidade de produtos, é que a escolha vai estar relacionada com a motivação e a necessidade de cada sujeito, seguindo este raciocínio Barretto (2000, p. 19) salienta que:

[...] Segundo o critério da motivação, aparece uma quase infinita variedade de possibilidades, que podem ser agrupadas em duas grandes divisões, o turismo motivado pela busca de atrativos naturais e o turismo motivado pela busca de atrativos culturais.

Os atrativos culturais que são o patrimônio cultural que cada sociedade possui se tornam um mercado em potencial para ser utilizado pelo turismo. Para a Organização Mundial do Turismo (2003, p. 106), “uma motivação atual do turismo é a nostalgia ou o paralelo com sociedades antigas", em que afirmam que a busca pela cultura de outros povos é uma tendência a ser explorada pelo turismo.

Relacionando turismo com cultura, Barretto (2000, p. 19) define turismo cultural como sendo "todo turismo em que o principal atrativo não seja a natureza, mas algum aspecto da cultura humana". Para Gastal (2002, p. 121) a relação que existe entre a cultura e o turismo é que "a cultura apropriada pelo turismo é a cultura que gera produtos e manifestações concretas, sejam elas eruditas ou populares", observando as definições de Barretto e Gastal, conclui-se que a relação entre turismo e cultura é toda a manifestação humana que é explorada pelo turismo.

Mas ainda Menezes ${ }^{3}$ (1996 apud GASTAL 2002, p. 126) explica que "o valor cultural não está nas coisas, mas é produzido no jogo concreto das relações sociais", o mesmo autor chama atenção para o fato de que "não existem valores universais e permanentes. [...] os sistemas estáticos (que precisam ser considerados como sistemas perceptivos), são históricos, historicamente constituídos e se transformam sem cessar". (MENEZES $1996{ }^{4}$ apud GASTAL 2002, p. 126) A cultura de uma sociedade sempre está em transformação e desenvolvimento, e isso inclui a percepção de sua memória para promover a valorização de sua identidade e cultura. Gastal (2002, p. 127) menciona ainda que, "a cultura é a socialização, mas apenas enquanto lidar com a dinamicidade do simbólico". A cultura não pode ser vista de forma individualista, mas sim em todo

\footnotetext{
${ }^{3}$ MENEZES, U. Os usos culturais da cultura. In: YAZIGI, Eduardo et al (orgs). Turismo, espaço, paisagem e cultura. São Paulo: Hucitec, 1996.

${ }^{4}$ idem
} 
entorno em que ela é produzida e na capacidade de se tornar o símbolo de uma sociedade (gerando identidade).

Lima (2003, p. 62) assegura que o "turismo cultural integra a cultura enquanto processo e enquanto produto", o turismo teria assim a capacidade de estimular a valorização da cultura de uma sociedade.

\title{
4 TURISMO E PATRIMÔNIO CULTURAL INTERPRETADO
}

Para o turismo o patrimônio é um atrativo em potencial, e o seu uso como um segmento de mercado, contribui na preservação e valorização do patrimônio cultural seguindo todas as recomendações dos órgãos internacionais e nacionais responsáveis. Segundo Pellegrini Filho (2001, p. 97) durante a Conferência Geral da UNESCO (United Nations Educational, Scientific and Cultural Organization), realizada em Paris (1972), ficou definido que o patrimônio cultural é constituído de:

\begin{abstract}
Monumentos que são obras arquitetônicas, de escultura ou de pintura, monumentais, elementos ou estruturas de caráter arqueológico, inscrições, cavernas e grupos de elementos, que tenham um valor universal excepcional do ponto de vista da história, da arte ou da ciência; conjuntos que são grupos de construções, ilhadas ou reunidas, cuja arquitetura, unidade e integração na paisagem lhes dêem um valor universal excepcional do ponto de vista da história, da arte ou da ciência e lugares que apresentam as obras do homem ou obras conjuntas do homem e da natureza assim como zonas incluindo sítios arqueológicos que tenham um valor universal excepcional do ponto de vista histórico, estético, etnológico ou antropológico.
\end{abstract}

Atualmente o patrimônio cultural é muito mais abrangente, não engloba somente os bens tangíveis como as obras arquitetônicas, esculturas, pinturas, cavernas, entre outros, mas também tudo o que é produzido pelos indivíduos em toda a sociedade como danças, gastronomia, entre outros. O IPHAN (Instituto do Patrimônio Histórico e Artístico Nacional), já utiliza desta perspectiva do patrimônio cultural e a produção intangível e tangível da sociedade.

Segundo Camargo (2002), está havendo uma valorização de toda a cultura do indivíduo, não somente a cultura das classes mais abastadas como até pouco tempo atrás acontecia, mas de todas as classes. Esta valorização também é citada por Barretto (2000, p. 45) quando explica que: 
[...] A noção de patrimônio cultural é muito mais ampla, que inclui não só os bens tangíveis como também os intangíveis, não só as manifestações artísticas, mas todo o fazer humano, e não só aquilo que representa a cultura das classes mais abastadas, mas também o que representa a cultura dos menos abastados.

Nesta afirmação de Barretto, patrimônio cultural abrange toda a manifestação da sociedade não somente os bens materiais, como imateriais, por exemplo, a fabricação de algum artesanato, o processo de fabricação em si. Dentro do patrimônio cultural entra o patrimônio histórico, mesmo que nem todo patrimônio cultural seja necessariamente histórico.

Todo patrimônio histórico transmite uma história de como era a sociedade na época em que foi construído, a economia, a arquitetura, os costumes, enfim todas as características da cultura da sociedade. A capacidade desta mensagem chegar ao visitante se chama interpretação do patrimônio. A esse respeito, Goodney e Murta (2002, p. 13) esclarecem que:

[...] A interpretação do patrimônio, em sua melhor versão, cumpre uma dupla função de valorização. De um lado, valoriza a experiência do visitante, levando-o a uma melhor compreensão e apreciação do lugar visitado; do outro, valoriza o próprio patrimônio, incorporando-o como atração turística.

O patrimônio cultural é entendido como sinônimo de identidade, memória, monumentos, símbolos e valores. A identidade de uma sociedade é a relação que ela tem com o patrimônio cultural com a qual se identifica. Gonçalves ${ }^{5}(1988$, p. 267 apud BARRETTO, 2000, p. 10) explicita que:

\begin{abstract}
Assim como a identidade de um indivíduo ou de uma família pode ser definida pela posse de objetos que foram herdados e que permanecem na família por várias gerações, também a identidade de uma nação pode ser definida pelos seus monumentos - aquele conjunto de bens culturais associados ao passado nacional. Esses bens constituem um tipo especial de propriedade: a eles se atribui a capacidade de evocar o passado e, desse modo, estabelecer uma ligação entre passado, presente e futuro. Em outras palavras, eles garantem a continuidade da nação no tempo.
\end{abstract}

${ }^{5}$ GONÇALVES, JR. Autenticidade, memória e ideologias nacionais: o problema dos patrimônios culturais. Estudos Históricos 1[2], 1988. 
Este símbolo de identidade só faz com que o patrimônio cultural seja cada vez mais valorizado e com isso perpetuado na história de uma sociedade tanto no passado, no presente e principalmente para novas gerações.

A função do turismo com o patrimônio cultural é tentar manter viva a memória, pela qual um povo mantém sua identidade. Le Goff ${ }^{6}$ (1990, p. 476 apud BARRETTO, 2000, p. 43) "a memória é um elemento essencial do que se costuma chamar identidade, individual ou coletiva, cuja busca é uma das atividades fundamentais dos indivíduos e das sociedades de hoje, na febre e na angústia". Manter viva essa memória é fundamental para a sociedade valorizar a sua cultura.

Barretto (2000, p. 43) relata que "a manutenção do patrimônio histórico, em sentido amplo, faz parte de um processo maior ainda, que são a conservação e a recuperação da memória, graças à qual os povos mantêm sua identidade". E o turismo planejado de forma responsável, faz com que a memória, a identidade seja conservada e cada vez mais valorizada. Barretto (2000, p. 44) ressalta o estímulo que a conservação do patrimônio propicia a sociedade:

A recriação dos espaços revitalizados, se bem realizada, apóia-se na memória coletiva e, ao mesmo tempo, estimula-a, já que ela é o motor fundamental para desencadear o processo de identificação do cidadão com sua história e sua cultura.

Este processo de conservação do patrimônio cultural está diretamente relacionado com a sua utilização, muitos especialistas explicam que dar uso ao patrimônio faz com que ele ganhe propósito para continuar a existir, por causa desta conservação é que a valorização do patrimônio ocorre, que está ligado diretamente à identidade de uma comunidade.

\section{TURISMO E PLANEJAMENTO INTERPRETATIVO}

Em virtude do constante crescimento do turismo, não é aceitável existirem projetos sem um planejamento baseado nas diretrizes da sustentabilidade do meio

\footnotetext{
${ }^{6}$ LE GOFF, J. História e memória. Campinas: Unicamp, 1990.
} 
natural e cultural. Para que exista um desenvolvimento equilibrado do turismo e harmonioso com todos os recursos físicos, culturais e sociais.

O planejamento consiste em estipular métodos a serem seguidos para alcançar objetivos propostos antecipadamente. Segundo Ruschmann (1997, p. 9) na área do turismo um planejamento tem a finalidade de "ordenar as ações do homem sobre o território e ocupa-se em direcionar a construção de equipamentos e facilidades de forma adequada evitando, dessa forma, efeitos negativos no recurso". O principal objetivo do planejamento é guiar o sujeito para que os impactos na comunidade receptora sejam minimizados, e que os impactos positivos sejam maximizados.

Segundo Goodney e Murta (2002, p. 16) o

\begin{abstract}
Turismo sustentado deve voltar-se para harmonizar as necessidades de seus quatro componentes: a comunidade receptora, os visitantes, o meio ambiente e a própria atividade turística. [...] o turismo pode ter um impacto positivo e ser catalisador da restauração, conservação e revitalização de ambientes naturais e culturais, reforçando a cultura local e contribuindo para a geração de empregos e renda nas comunidades.
\end{abstract}

O planejamento é importante para construir harmonia entre a comunidade, os visitantes, com o meio ambiente e com a atividade turística, pois, propicia a valorização e proteção da cultura. Para Barretto (2000, p. 76) "o planejador de turismo pode fazer um trabalho científico, capaz de dosar a quantidade de turistas que pode receber sem saturá-lo e sem que a população se sinta invadida”. A mesma autora ainda alerta que "um princípio que vem sendo aplicado ao planejamento do turismo de natureza deve ser aplicado ao planejamento do turismo com base no legado cultural: o da sustentabilidade" (2000, p. 77). Uma forma de estratégia do planejamento sustentável no turismo é a qual Goodney e Murta (2002) chamam de planejamento interpretativo.

O planejamento interpretativo deve contar com a participação da comunidade em todo o processo de reconhecimento do patrimônio, com ajuda de toda a comunidade que prevê uma estratégia de coordenação e implantação da interpretação fazendo que todos trabalhem em parceria. Segundo Goodney e Murta (2002, p. 22) "o plano de interpretação ambiental com a participação da comunidade tornou-se comum, passando a influenciar decisivamente o próprio desenho urbano". A idéia de tornar a comunidade parte do processo de planejar no caso do patrimônio cultural faz com que o planejamento proteja e desenvolva um sentimento de valorização, de transmitir seus 
valores, e suas histórias para as gerações futuras. O planejamento interpretativo segundo Goodney e Murta (2002, p. 22)

\begin{abstract}
Orienta a limpeza e a descoberta de fachadas originais, a harmonia da sinalização e do desenho de placas e letreiros compatíveis com o "espírito" do lugar, das trilhas pela malha urbana que "decifram" a cidade e das placas informativas que ampliam a percepção ambiental do visitante. Também no âmbito de museus e casas históricas, a interpretação, realizada com o uso de sedutoras técnicas interativas, amplia a compreensão popular sobre sítios e coleções históricas.
\end{abstract}

Este planejamento quando realizado com sucesso, torna os ambientes comuns mais desfrutados, apreciados, administrados, protegidos e valorizados. Prédios que antes não eram valorizados se tornam atrativos. Exemplo do uso do planejamento interpretativo foi organizado em Barcelona para as Olimpíadas de 92, que utilizou o planejamento interpretativo como estratégia de desenvolvimento (GOODNEY e MURTA, 2002).

No processo de interpretação do patrimônio, Farias (2002, p. 59) complementa dizendo que "ao processo interpretativo agregam-se fontes de revelação baseadas no imaginário: mitos, ritos, arquétipos, símbolos, ícones, alegorias, cotidiano, cotidianidade e lugar", o autor mostra a necessidade que a comunidade, onde está ocorrendo o planejamento, participe ativamente de todo o processo de interpretação, identificação e valorização do patrimônio.

Sobre o tema, em Cardozo (2007, p. 4) tem-se que:

A interpretação do patrimônio visa otimizar a visita, desde o ponto de vista do visitante, fornecendo informações sobre os lugares visitados e também estimulando o olhar, provocando a curiosidade levando assim o turista a descobrir toda a magia do lugar.

Nesta perspectiva em que a interpretação do patrimônio é fazer com que o turista descubra toda a singularidade do local, segundo Cardozo (2007, p. 4) a interpretação tem outra função que não só a descoberta, mas também "mais do que informar, a interpretação tem como objetivo conscientizar as pessoas do valor tangível e intangível do patrimônio", essa conscientização não é somente para os turistas, mas para toda a comunidade. 
Cabe ao planejador do turismo identificar toda a singularidade de um local, para que o turista desperte o sentimento de valorização e conscientização de todo patrimônio visitado.

O planejamento interpretativo que começou a ser utilizado no Brasil no final da década de 90 traz vantagens para a localidade em que é aplicado, por ter princípios de sustentabilidade e trabalhar em conjunto com a comunidade local, faz com que esse novo estilo de planejamento tenha grande sucesso quando implantado, e o estudo deste tema atual pode auxiliar novos pesquisadores a aprofundar conhecimentos em planejamento.

\section{APRESENTAÇÃO E DESCRIÇÃO DAS EDIFICAÇÕES INVENTARIADAS NA PESQUISA}

Os dados obtidos por meio do formulário e das entrevistas em cada edifício foram contextualizados para facilitar a identificação das singularidades de cada edifício, conforme segue resumo das informações. Para detalhes ver apêndice:

MUSEU DA SINHARA (Tombamento Estadual): O imóvel situa-se entre as ruas Dr. Francisco Xavier da Silva e José Carneiro. Atualmente nele funciona o Museu da Sinhara. Com entrada gratuita, recebe aproximadamente 1.000 pessoas por mês (MUSEU DO TROPEIRO, 2007).

CASA DA FAMílIA FONSECA I (Tombamento Estadual): Localizada na Praça Manoel Ribas, 112 e 120, possui um acesso sinalizado. Inicialmente era casa de comércio e residência, sob arquitetura de transição entre o colonial e o neoclássico. Atualmente atende fins comerciais de locação.

CASA DE PEDRA (Tombamento estadual): Localizada na Praça Manoel Ribas 150, tem acesso sinalizado. Construída em estilo de transição entre o colonial e neoclássico. Atualmente, funciona como locadora de vídeos, e residência da proprietária, não possuindo nenhum equipamento turístico.

CASA DE CULTURA (Tombamento estadual): Localizada na Rua Dr. Jorge Xavier da Silva, 454. Com acesso bem sinalizado já possui fluxo turístico. Edificação 
em taipa, provavelmente da década inicial do século XIX. Atualmente funciona o arquivo municipal, e a casa de cultura, com espaço para cursos, exposições, entre outros eventos do cunho cultural, que está sob responsabilidade da prefeitura.

CASA DA FAMÍLIA FONSECA II: Edifício não tombado está localizado na Rua Pandiá Calógeras, 122, possui acesso bem sinalizado. É uma construção de estilo de transição do colonial português para o neoclássico. $\mathrm{O}$ edifício não tem nenhum equipamento turístico, atualmente a casa está em processo de revitalização onde todos os traços originais estão sendo mantidos.

RESIDÊNCIA DA FAMÍLIA MACEDO: Edifício não tombado, localizado na Rua Pandiá Calógeras 177, com acesso bem sinalizado. A casa segue o estilo de transição com características singulares. Atualmente o edifício funciona como moradia.

RESIDÊNCIA DA FAMÍlIA CARNEIRO DE MELLO: Edifício não tombado está localizado na Rua Dr. Jorge Xavier da Silva 81, tem o acesso bem sinalizado. Conta com estilo de transição do colonial para o neoclássico. Atualmente a casa está abandonada, em processo de desapropriação.

CASA DA FAMília ROLIM DE MOURA: Edifício não tombado, construído na antiga Rua Direita em meados do século XIX, atualmente Rua Xavier da Silva, 66, tem o acesso bem sinalizado. Construída num misto de paredes de estuque e tijolos maciços e argamassa. A proprietária não tem nenhum interesse no turismo. Atualmente funciona como moradia e não possui nenhum equipamento turístico.

CASA DA FAMíLIA PUSCH: Edifício não tombado está localizado na Rua Bernardo Pusch, mas tem o seu acesso pouco sinalizado, foi construído em 1918. O edifício representa o auge do ciclo industrial ocorrido em Castro nas primeiras décadas do século XX. Atualmente a casa está de posse de uma das herdeiras.

CASA DA FAMÍlia CARNEIRO LOBO - MUSEU DO TROPEIRO (Tombamento estadual): O atual Museu do Tropeiro está localizado na Praça Sant'Ana, 11, antiga praça Getúlio Vargas, no entorno da Matriz de Sant'Ana, tem o seu acesso bem sinalizado. $\mathrm{O}$ edifício é em estilo colonial português. Atualmente funciona o Museu do Tropeiro, o único a ter um acervo específico do ciclo do tropeirismo no Brasil.

CASA DA FAMÍLIA PRESTES: Edifício não tombado está localizado na Rua Xavier da Silva, 231, a antiga Rua Direita, tem como ponto de referência a Casa de 
Sinhara por isso tem o seu acesso bem sinalizado, utilizado para fins de moradia, mantém o estilo de transição entre o colonial e o neoclássico. Está em estado de conservação de regular para ruim, com nenhuma facilidade ou equipamento turístico.

CASA DA FAMíLIA VILLELA: Edifício não tombado se encontra em estado de conservação precário, localizada na Praça Pedro Kaled, 23, mas bem sinalizada. A metade da casa está alugada e outra metade fechada, não possui nenhum equipamento ou facilidades para turismo.

CASA E MERCEARIA DA FAMílIA QUADROS: Nenhum dos edifícios é tombado, a atual casa e a mercearia foram construídas em 1918 e 1928 respectivamente, onde só se encontram as fachadas originais. Estão localizadas na Praça Pedro Kaled, 38 e 32. Atualmente foram transformadas em escritórios no térreo e apartamentos no primeiro andar.

GRANDE HOTEL: Edifício não tombado, localizado na Rua Cipriano Marques, 44, rua movimentada e possui boa sinalização, a obra está em bom estado de conservação. Utilizado por viajantes o hotel é de pequeno porte.

CASA DA FAMílIA CAXAMBU: Edifício não tombado foi construído no início do século XIX, localizada na Praça João Gualberto 144, bem sinalizada. Encontra-se em ótimo estado de conservação e é aberta à visitação gratuita a partir de 15 de Dezembro até o dia 6 de Janeiro.

CASA DA FAMÍLIA TELLES: Edifício não tombado, construído em meados do século XIX, localizada na Rua Dr. Jorge Xavier da Silva, 568, está em processo de restauração. Atualmente funciona uma escola.

CASAS GÊMEAS (ROLIM DE MOURA): Edifícios não tombados, construídos no final do século XIX. Estão localizadas na Rua Romário Martins, 620 e 610. Com quase nenhuma sinalização, a primeira foi completamente adaptada para o funcionamento de uma rádio. A outra funciona como residência.

CASA DA FAMÍLIA KALED: Edifício não tombado, construído no final do século XIX, na Rua Romário Martins, 546. Sem nenhum tipo de sinalização, a casa se encontra em estado de conservação precário.

CASA DA FAMíliA MOROZ: Provavelmente construída em meados do século XIX, localizada na Rua Romário Martinz, 965 com pouca sinalização. Utilizada 
como residência, conserva praticamente todas as suas características originais, onde já foram gravadas cenas de vários filmes que retratam a fase do tropeirismo.

CASA DA FAMílIA GREISS: Edifício não tombado foi construído em meados do século XIX, localizada na Rua Romário Martins, 477 com pouca sinalização. Encontra-se em ótimo estado de conservação. Utilizada somente para residência.

CASA CENTENÁRIA: Edifício não tombado, construído no final do século XIX, localizada na Rua Dr. Jorge Xavier da Silva, 12 e 16 com boa sinalização. Na época da pesquisa se encontrava à venda e num estado muito precário.

CASA UCRANIANA: Edifício não tombado, provavelmente construído no início do século XX, bem conservada onde atualmente funciona uma repartição pública.

CASA DA LATORRE: Edifício não tombado, a casa está em ótimo estado de conservação, mas pouco de seus elementos originais foram mantidos, localizada na Rua Padre Nicolau Baltazar, 177. Tem sinalização geral e turística pouco eficiente. É aberta à visitação, mas não é adaptada para receber grupos grandes de visitantes.

Pôde-se observar que os edifícios identificados foram construídos no ciclo do tropeirismo. As tropas que vinham do sul do país, Argentina e Uruguai tinham a cidade de Castro como pouso para as tropas. Sobre a colonização a proprietária e neta de tropeiro M. L. M. mencionou que "o patrimônio arquitetônico de Castro reflete a sua história, seus costumes, seu desenvolvimento, sua evolução, sua participação na história paranaense, estilos de construção empregados em diversas épocas" com essa diversidade cultural o patrimônio histórico arquitetônico tem a sua singularidade.

Constatou-se que 22 edifícios de um total de 23 têm o estilo de construção definido como de transição de colonial português para neoclássico, construídos entre 1820 e 1920, os edifícios construídos nesse período são os que demonstram maior importância para o patrimônio histórico devido às suas singularidades, pois foram construídos por imigrantes, onde expressaram a sua cultura na arquitetura dos edifícios. Somente um edifício restou com o estilo colonial português que data de meados do século XVIII onde atualmente funciona o museu do tropeiro.

Foi identificado um fluxo turístico expressivo no Museu do Tropeiro, Museu da Sinhara e Casa da Praça em média 1.000 pessoas por mês em cada museu (MUSEU DO TROPEIRO, 2007, s/p), não existindo nenhum tipo de planejamento turístico para a 
região. Isso faz com que o turista não valorize todo esse patrimônio como deveria, e faz ainda com que este patrimônio não seja aproveitado em sua amplitude. Mas para isso acontecer a comunidade da cidade tem a necessidade de valorizar todo esse patrimônio, como a proprietária H. B. P. falou "temos a obrigação de cuidar de todas as edificações existentes", essa idéia de preservação do patrimônio foi comum a 20 proprietários, ainda H. B. P. disse que "pessoas da minha geração principalmente e também mais jovem têm sentimento pela cidade", a entrevista revelou que existiam muitas pessoas interessadas em preservar o patrimônio.

Observou-se que já existia um pequeno fluxo de turistas na região central de Castro, devido aos três prédios nos quais foram dados usos culturais e turísticos que são: o Museu do Tropeiro, Museu da Sinhara e a Casa da Praça, mas existia um crescimento desequilibrado por falta de planejamento, causando impactos sociais e ao patrimônio. Nesse sentindo caberiam ações de planejamento interpretativo não só desses 3 edifícios, onde já se observou existir fluxo turístico, mas todo o patrimônio identificado e outros que não fazem parte da região estudada, para que a sociedade da cidade valorize ainda mais o seu patrimônio e o turista tenha o maior proveito do patrimônio cultural arquitetônico.

Constatou-se existir uma dificuldade de uso do patrimônio histórico arquitetônico pelo turismo devido à falta de conhecimento dos proprietários, mas não que não eram totalmente contrários ao turismo em suas propriedades, para a proprietária M. L. M, de 76 anos, o patrimônio cultural histórico de Castro "pode sim, tornar-se um atrativo turístico pela sua amplitude, pelo grande número de edificações antigas que datam do século XVIII, pela sua cultura miscigenada", com esta perspectiva a idéia de um planejamento interpretativo do patrimônio vem auxiliar a necessidade de valorização e preservação do mesmo.

Concluiu-se, que o potencial turístico de Castro é relevante. Podem-se reconhecer através da coleta dos dados, os edifícios históricos, e sua potencialidade turística, fazendo com que estes dados sejam valiosos não somente para este estudo, como também para todo aquele preocupado com a questão. 


\section{CONSIDERAÇÕES FINAIS}

O presente trabalho objetivou refletir sobre um possível planejamento interpretativo do patrimônio cultural histórico e arquitetônico do centro da cidade de Castro. Para tanto, houve um levantamento e análise de todo esse tipo de patrimônio arquitetônico. Partindo do princípio que patrimônio cultural pode ser compreendido como sendo todos os bens tangíveis e intangíveis que um indivíduo produz, e que tenham valor sob ponto de vista histórico, estético, antropológico e etnológico, este requer um planejamento específico para sua valorização e uso turístico. Nesse sentido o planejamento interpretativo pode ser utilizado, pois ele visa otimizar a visita, a partir do ponto de vista do turista, disponibilizando informações dos pontos visitados e estimulando o olhar, incitando a curiosidade fazendo com que o turista desvende a aura do lugar. Sob estas perspectivas teóricas é que se lançou um olhar sobre o patrimônio cultural histórico e arquitetônico, com a finalidade de orientar a implementação de políticas públicas no que tange ao planejamento interpretativo do patrimônio arquitetônico da cidade, que se deu por meio de estudos dos preceitos de planejamento turístico à luz da interpretação patrimonial, identificação do patrimônio cultural arquitetônico local e inventariação do patrimônio cultural arquitetônico.

Pode-se aferir que o patrimônio cultural histórico e arquitetônico de Castro tem possibilidades de utilização turística, mas em suas devidas limitações. Assim sendo, e a fim de alcançar com êxito os objetivos propostos, estas considerações apresentam algumas orientações para elaboração de políticas e planos de turismo interpretativo para este patrimônio:

- Utilizar um dos edifícios pesquisados para ser um centro de visitação, sendo base das rotas e trilhas, podendo concentrar várias informações e painéis explicativos, com sanitários, bares, restaurantes e lojas de suvenires;

- A iluminação especial de tal patrimônio teria um grande impacto no visitante, pois possibilitaria apresentar o patrimônio através de um show de luzes, ou simplesmente mostrar o atrativo à noite e assim provocando ainda mais a 
curiosidade do visitante e da própria comunidade a fim de valorizar o patrimônio;

- Montar diversos roteiros e trilhas auto-guiados com placas informativas sobre os diversos pontos de interesse, com base no tempo, meio de deslocamento e distância, assim poderiam ser formatados vários roteiros para os diversos tipos de turistas;

- Criar material de divulgação com imagens e partes da história do local folhetos, mapas, painéis, placas e guias ilustrados com informações claras, que poderiam ser utilizados tanto para os moradores como para os turistas;

- Envolver a comunidade local, especialmente os proprietários no processo de planejar - faria com que fossem identificados os pontos mais relevantes e que poderiam ser utilizados pelo turismo, e assim criando um sentimento de valorização do patrimônio, e incentivando ao restauro e a preservação;

- Incentivar a restauração e revitalização dos edifícios para que a identidade da comunidade não se perca, e com a possibilidade de uso pelo turismo;

- Tombar para preservar - por meio de palestras e eventos esclarecer os benefícios e os motivos sobre o tombamento que poderiam trazer aos proprietários e a toda comunidade, para que não se perca toda a história e cultura da cidade de Castro;

- Incentivar o uso das edificações ou parte delas pelo turismo, como por exemplo, restaurantes, bares, comércio em geral.

O planejamento interpretativo tem como base a participação da comunidade em todo o processo, fazendo com que todos os integrantes de uma sociedade trabalhem em conjunto (órgãos públicos, privados e moradores), de modo que se desenvolva um sentimento de valorização, de transmissão de seus valores e suas histórias para os turistas. Assim sendo, e de forma a finalizar a reflexão, distante de ser um planejamento perfeito, esse trabalho pode ser discutido na academia e pelos interessados na gestão do patrimônio, que poderão utilizá-lo para elaborar planos de ações concretas e assim satisfazer as necessidades dos turistas e dos castrenses, e ao poder público, cada qual em seu domínio. 


\section{REFERÊNCIAS}

BARRETTO, M. Turismo e legado cultural. Campinas, SP: Papirus, 2000.

CAMARGO, A. L. Patrimônio histórico e cultural. São Paulo: Aleph, 2002.

CARDOZO, P. F. Interpretação patrimonial: indicações de um plano interpretativo para a mesquita Omar Ibn Khatab do Foz do Iguaçu - PR. In: Anais do II EPHTUR. CDROM. Ponta Grossa, 2007.

FARIAS, E. K. V. A construção de atrativos turísticos com a comunidade. In: ALBANO, C.; MURTA, S. (orgs.). Interpretação do patrimônio: um exercício do olhar. Belo Horizonte: Editora da UFMG; Território Brasilis, 2002.

GASTAL, S. Turismo \& Cultura: por uma relação sem diletantismos. In: Edpucrs, 2002. (org). Turismo: 9 propostas pra um saber-fazer. Porto Alegre:

GOODNEY, B.; MURTA, S. Interpretação do patrimônio para visitantes: um quadro conceitual. In: ALBANO, C.; MURTA, S. (orgs). Interpretação do patrimônio: um exercício do olhar. Belo Horizonte, Editora da UFMG; Território Brasilis, 2002.

LIMA, C. Turismo cultural: que formação? In: GASTAL, S., CASTROGIOVANNI, A. C. (orgs.). Turismo na pós-modernidade (des)inquietações. Porto Alegre: EDIPUCRS, 2003.

MUSEU DO TROPEIRO. Caderno de visitas. (documento). 2007

ORGANIZAÇÃO MUNDIAL DO TURISMO. Turismo internacional: uma perspectiva global. Porto Alegre: Bookman, 2003.

PELLEGRINI FILHO, A. Ecologia, cultura e turismo. 7. ed. Campinas: Papirus, 2001.

RUSCHMANN, D. v. d. M. Turismo e planejamento sustentável: a proteção do meio ambiente. Campinas: Papirus, 1997. 


\section{APÊNDICE}

\section{Edificações estudadas:}

MUSEU DA SINHARA (Tombamento Estadual): Com a fachada principal voltada para a Praça Sant'Ana, o imóvel ocupa toda extensão do terreno situado entre as ruas Dr. Francisco Xavier da Silva e José Carneiro. Construída em alvenaria de pedra e taipa, seus elementos confirmam o partido adotado pela arquitetura de transição entre o colonial e neoclássico. A casa sofreu várias intervenções, as quais, entretanto, não a descaracterizaram: ampliação para instalação de banheiros e um quarto, fechamento de alguns vãos e substituição de telhado original por outro de telhas francesas. As esquadrias, internas e externas, a maior parte do forro e o piso são, ainda, originais. Atualmente nela funciona o Museu da Sinhara que tem seu acervo voltado completamente à mulher do tropeiro, seus usos e costumes. Com entrada gratuita, o museu recebe aproximadamente 1.000 pessoas por mês.

CASA DA FAMÍLIA FONSECA I (Tombamento Estadual): Localizada na Praça Manoel Ribas, 112 e 120, possui um acesso bem sinalizado. Primitivamente casa de comércio e residência, adota o partido da arquitetura de transição entre o colonial e o neoclássico, e ao ser concluída possuía cinco portas na fachada frontal, três das quais foram transformadas em janelas, quando da adaptação do imóvel, o que motivou também uma ampliação da parte posterior para construção de cozinha com fins residenciais. A casa possui ainda o telhado original, bem como grande parte das primitivas esquadrias. Construída em alvenaria de pedra por João José da Fonseca, afigura-se como monumento histórico do ciclo tropeiro e imperial da província do Paraná e talvez já fizesse parte da paisagem da cidade quando da visita do imperador Pedro II, em maio de 1880. O edifício não possui nenhum equipamento turístico. Atualmente o proprietário o dividiu em dois, onde aluga um lado para um jornal e o outro lado para uma rádio.

CASA DE PEDRA (Tombamento estadual): Localizada na Praça Manoel Ribas 150, tem acesso bem sinalizado. Construída em alvenaria de pedra argamassa e com paredes internas de pau-a-pique, o imóvel se situa dentro do partido adotado pela arquitetura de transição entre o colonial e neoclássico, mesclando elementos de ambos os estilos. Apesar de ter sofrido intervenções (substituição de trecho do telhado original, na parte posterior da edificação, e modificações na divisão interna), mantém ainda grande parte dos elementos originais. Conta-se ter sido a casa construída por um escravo ao qual fora prometida a alforria em troca do trabalho. Todavia, quando da conclusão da obra, foi ele vendido, a fim de continuar a ser escravo-construtor. Segundo as pesquisas feitas nos arquivos do Museu do Tropeiro neste edifício já funcionou um hotel. Nos dias de hoje, funciona como locadora de vídeos, e residência da proprietária, não possuindo nenhum equipamento turístico.

CASA DE CULTURA (Tombamento estadual): Localizada na Rua Dr. Jorge Xavier da Silva, 454. Com acesso bem sinalizado já possui um fluxo turístico. Edificação em taipa, provavelmente da década inicial do século XIX. Nesta casa funcionou o primeiro jardim de infância particular do Brasil, dirigido pela educadora Emília Erichsen. Construída sobre planta retangular, a edificação tem sua fachada principal emoldurada por cunhais de massa, aberturas (uma porta e quatro janelas) enquadradas por requadros em madeira e encimadas por vergas retas: janelas em sistema de guilhotina, divididas em quadrículos, e postigos internos. Cobertura em telhado de quatro águas, telha canal, arrematada por beiral em cimalha. Atualmente funciona o arquivo municipal, e a casa de cultura, com espaço para cursos, exposições, entre outros eventos do cunho cultural, que está sob responsabilidade da prefeitura.

CASA DA FAMÍLIA FONSECA II: Edifício não tombado está localizado na Rua Pandiá Calógeras, 122. Próximo à Praça Manoel Ribas possui acesso bem sinalizado. Joaquim Anacleto da Fonseca requereu em 1840 o terreno em frente o Pelourinho para formar sua propriedade. É uma construção de estilo de transição do colonial português para o neoclássico, com paredes de estuque, com fino acabamento interior, onde até pouco tempo a pintura imitando mármore poderia ser vista nas paredes de entrada. A sala de visita sugere a lembrança dos saraus familiares, pois possui o forro original, que é considerado um dos mais belos de todos os casarões da época. O edifício não tem nenhum equipamento turístico, atualmente a casa está em processo de revitalização onde todos os traços originais estão sendo mantidos. 
RESIDÊNCIA DA FAMÍLIA MACEDO: Edifício não tombado, localizado na Rua Pandiá Calógeras 177. Próximo à Praça Manoel Ribas tem um acesso bem sinalizado. Em terrenos requeridos em 1866, Joaquim Anacleto da Fonseca edificou a residência para Zita Fonseca Marques, esposa de Affonso Marques de Sousa. Mais tarde a propriedade foi transferida a Dario de Macedo, permanecendo na família pelas gerações seguintes. A casa segue o estilo de transição com características singulares, no auge da Família Macedo a casa era considerada uma das mais bonitas, pelos detalhes que ali existiam. Atualmente o edifício não está mais com a família Macedo, mas funciona como moradia. Construída em tijolo maciço e argamassa, ela esta bem conservada, mas com alguns detalhes que estão em processo de revitalização, como caixilhos, janelas, portas e parte do forro.

RESIDÊNCIA DA FAMÍLIA CARNEIRO DE MELLO: Edifício não tombado está localizado na Rua Dr. Jorge Xavier da Silva 81. Essa rua também conhecida como a Antiga Rua das Tropas tem o acesso bem sinalizado. Pertenceu a Cândido de Oliveira Mello, que em 1919 a transferiu para Vespasiano Carneiro de Mello, foi um dos principais prefeitos de Castro, teve vários mandatos à frente da prefeitura. A casa foi então reformada, eliminando-se as cavalariças existentes na saída para a Rua das Flores. Atualmente a casa está abandonada, é uma casa imponente por suas características singulares, o jardim que possui o mesmo traçado onde existiam plantas de todas as partes do mundo, tem um estilo de transição do colonial para o neoclássico, considerada uma das mais belas edificações da cidade. A tradição da família era a de manter as portas da frente sempre abertas, em época de eleições eram servidos grandes banquetes para os eleitores. Atualmente o edifício se encontra fechado e abandonado, em processo de desapropriação.

CASA DA FAMÍLIA ROLIM DE MOURA: Edifício não tombado, construído na antiga Rua Direita em meados do século XIX, atualmente Rua Xavier da Silva, 66 por Antonio Rolim de Moura, próxima à Prefeitura Municipal, tem o acesso bem sinalizado. Construída num misto de paredes de estuque e tijolos maciços e argamassa, a casa possui dois pavimentos, preservando todas as características da época. Conserva na sala de visitas mobiliário da época, aparelho de chá e café, em prata, além de um piano do séc. XIX com o testemunho da vida social da família. A proprietária não tem nenhum interesse no turismo. Atualmente funciona como moradia e não possui nenhum equipamento turístico.

CASA DA FAMíLIA PUSCH: Edifício não tombado está localizado na Rua Bernardo Pusch próximo à Prefeitura municipal, mas tem o seu acesso pouco sinalizado, foi construído em 1918 pelo industrial Bernardo Pusch, que coordenou pessoalmente os trabalhos de edificação. A casa foi construída por um alemão com traços da cultura italiana, provavelmente o construtor veio da Europa especialmente para a construção desta casa, e um artesão italiano para fazer o acabamento. O edifício representa o auge do ciclo industrial ocorrido em Castro nas primeiras décadas do século XX. Atualmente a casa está com uma das herdeiras, que adquiriu a casa em 1974, em 2001 passou por uma reforma onde os principais traços foram mantidos, como portas, janelas, porão, forros e a fachada.

CASA DA FAMÍLIA CARNEIRO LOBO - MUSEU DO TROPEIRO (Tombamento estadual): O atual Museu do Tropeiro está localizado na Praça Sant'Ana, 11, antiga Praça Getúlio Vargas, no entorno da Matriz de Sant'Ana, tem o seu acesso bem sinalizado. Seguindo o estilo da colonização portuguesa que tem essas características, o edifício de estilo colonial, preserva os traços de como foi edificado. Foi construído no início do século XVIII por Hermógenes Carneiro Lobo, e vendido 1965 para o vigário local, padre Damasco, esse são os relatos mais antigos da casa e de seus primeiros proprietários. A casa foi construída com paredes de taipa, vigamento em madeiras falquejadas e a cobertura em telha canal. Atualmente no edifício funciona o Museu do Tropeiro, o único museu a ter um acervo específico do ciclo do tropeirismo no Brasil, que é mantido pela Associação Amigos do Museu e Prefeitura Municipal de Castro.

CASA DA FAMílIA PRESTES: Edifício não tombado está localizado na Rua Xavier da Silva, 231, a antiga rua Direita, construída no final do século XIX, tem como ponto de referência a Casa de Sinhara por isso tem o seu acesso bem sinalizado, somente utilizado para fins de moradia, é conhecido como Casa dos Prestes mantém o estilo de transição entre o colonial e o neoclássico. A casa está num estado de conservação de regular para ruim, com nenhuma facilidade ou equipamento turístico, mantendo todas as características da época de sua construção.

CASA DA FAMÍLIA VILLELA: Edifício não tombado, a casa se encontra em estado de conservação precário, localizada na Praça Pedro Kaled, 23. Próxima à Prefeitura Municipal está bem sinalizada. A propriedade se encontra de posse da família que está dividida em dois irmãos, metade da casa está alugada e outra metade fechada, não possui nenhum equipamento ou facilidades para turismo. Construída em meados do século XIX, atualmente, o edifício possui pouco das suas características originais, onde já funcionou como ponto de comércio e residência. 
CASA E MERCEARIA DA FAMÍLIA QUADROS: Nenhum dos edifícios é tombado, a atual casa e a mercearia foram construídas em 1918 e 1928 respectivamente, onde só se encontram as fachadas originais. Estão localizadas na Praça Pedro Kaled, 38 e 32. Construída por Eduardo José de Quadros, que foi um grande comerciante da região no final do século XIX e início do século XX, próxima à Prefeitura Municipal é bem sinalizada e não possui nenhum equipamento turístico. Atualmente a casa foi transformada em escritórios no térreo e apartamentos no primeiro andar. A mercearia, também foi completamente reconstruída, permanecendo somente a fachada, que foi construída em 1928, ao lado da residência. $\mathrm{O}$ atual proprietário aluga para uma loja de confecções.

GRANDE HOTEL: Edifício não tombado, localizado na Rua Cipriano Marques, 44. Construído no início do século XIX, tinha a finalidade de hotel, está em uma rua bem movimentada possui uma boa sinalização, em bom estado de conservação passou por várias reformas onde alguns de seus elementos originais foram mantidos, mas por falta de conhecimento do proprietário o hotel não é adaptado para receber turistas com qualquer tipo de deficiência. Utilizado por viajantes o hotel é de pequeno porte, mas por falta de informação do proprietário não foi feita uma pesquisa mais aprofundada.

CASA DA FAMÍlIA CAXAMBU: Edifício não tombado, a casa foi construída no início do século XIX, por Filizzola Caxambu, localizada na Praça João Gualberto 144, bem sinalizada. Foi construída em tijolo e argamassa, mantém todas as características, desde a fachada até as pinturas no interior da casa (textura portuguesa), uma das únicas casas a manter essa característica. Em ótimo estado de conservação, as proprietárias atuais têm uma tradição que na época de Natal, quando montam um pinheiro de 4 metros de altura dentro da sala e que é aberta à visitação gratuita a partir de 15 de Dezembro até o dia 6 de Janeiro, essa tradição já dura mais de 65 anos, e é costume dos visitantes deixarem um enfeite, por este fato a árvore possui enfeites de várias localidades do mundo.

CASA DA FAMíLIA TELLES: Edifício não tombado, construída em meados do século XIX, localizada na Rua Dr. Jorge Xavier da Silva, 568 pelo proprietário da casa Bancária Telles, com uma arquitetura única na cidade, com traços muitos marcantes. Estava abandonada até pouco tempo atrás, a casa está em processo de restauração, o proprietário faz questão de conservar a riqueza e as ostentações da família Telles. Atualmente funciona uma escola de inglês e música, a casa ainda possui forros e pisos originais, como também uma sala que possui pintura da época, que está em fase de recuperação.

CASAS GÊMEAS (ROLIM DE MOURA): Edifícios não tombados, construídos por Antonio Rolim de Moura no final do século XIX, provavelmente para serem vendidas, são casas gêmeas como a população as chama, possuem a mesma divisão de cômodos. Estão localizadas na Rua Romário Martins, 620 e 610. Com quase nenhuma sinalização, a primeira foi completamente adaptada para o funcionamento de uma rádio. A outra funciona como residência que foi deixada como herança para uma dama de companhia. As duas casas estão em bom estado de conservação, mantendo vários elementos originais.

CASA DA FAMíLIA KALED: Edifício não tombado, construído no final do século XIX, na Rua Romário Martins, 546. Sem nenhum tipo de sinalização, foi adquirida por Pedro Kaled em 1950, com ajuda do então prefeito Pedro Novaes, os dois foram grandes personalidades da vida política de Castro. Atualmente mora a filha de Pedro Kaled, a casa se encontra em estado de conservação muito precário, com paredes de estuque desmoronando. É uma casa de pouco expressão, considerando a época de construção em relação às outras do mesmo período.

CASA DA FAMÍLIA MOROZ: Uma das casas em que não foi possível levantar sua história, provavelmente construída em meados do século XIX, pouco se sabe sobre ela, comprada por Antip Moroz há mais de 30 anos, localizada na Rua Romário Martinz, 965 com pouca sinalização. Utilizada somente como residência, conserva praticamente todas as suas características originais, onde já foram gravadas cenas de vários filmes que retratam a fase do tropeirismo.

CASA DA FAMílIA GREISS: Edifício não tombado foi construído em meados do século XIX, localizada na Rua Romário Martins, 477 com pouca sinalização. Pertenceu a Maria Greiss, em ótimo estado de conservação, construída em estuque mantém seus elementos originais. Utilizada somente para residência, este edifício tem um fato interessante, quando o atual proprietário comprou a casa, fez uma contrato com a antiga moradora que teria uso vitalício sobre o imóvel, já que não tinha deixado nenhum herdeiro.

CASA CENTENÁRIA: Edifício não tombado, construído no final do século XIX, conhecido como a "Casa Centenária", onde o atual proprietário que é um conhecedor da história do tropeirismo fez questão de ressaltar o valor histórico da casa localizada na Rua Dr. Jorge Xavier da Silva, 12 e 16 com boa sinalização. Teve dupla função ao passar dos anos como residência e comércio, a conservação da casa que se encontra à venda está muito precária, muitos elementos já foram perdidos por falta de condições financeiras para preservar como era originalmente. 
CASA UCRANIANA: Edifício não tombado, provavelmente construído no início do século $\mathrm{XX}$, por um imigrante de origem ucraniana, utilizando materiais mais modernos como tijolos maciços e argamassa, muito bem conservada pelo atual proprietário, que faz questão de manter todos os traços originais da casa, como os lambrequins, escada e afrescos nas paredes. Atualmente funciona uma repartição da prefeitura de auxilio psicológico.

CASA DA LATORRE: Edifício não tombado, pertence ao grupo Latorre que tem sede no interior de São Paulo, a casa esta em ótimo estado de conservação, mas pouco de seus elementos originais foram mantidos, localizada na Rua Padre Nicolau Baltazar, 177, próxima à Igreja Matriz de Sant'Ana. Tem uma sinalização geral e turística pouco eficiente, mesmo por estar muito próxima ao Museu do Tropeiro e Museu da Sinhara. É aberta à visitação, mas tem que marcar horário no escritório do grupo em Castro, a casa não é adaptada para receber grupos grandes de visitantes.

Recebido em: 29 de novembro de 2007

Aprovado em: 29 de dezembro de 2007 